\title{
Flexural performance of nano silica modified roller compacted rubbercrete
}

\author{
Musa Adamu*, Bashar S. Mohammed, Nasir Shafiq \\ Department of Civil and Environmental Engineering, Universiti Teknologi PETRONAS, 32610 Bandar Seri Iskandar, Perak, \\ Malaysia
}

\section{A R T I C L E I N F O}

\section{Article history:}

Received 16 May 2017

Received in revised form

20 July 2017

Accepted 25 July 2017

\section{Keywords:}

Crumb rubber

Nano silica

Roller compacted rubbercrete

Flexural toughness

Response surface methodology

\begin{abstract}
A B S T R A C T
Roller compacted concrete (RCC) has similar properties as conventional concrete; it is brittle, less ductile and has poor tensile strength. When used for pavement applications, it is also subjected to repetitive fatigue loads and flexural stresses. In addition, dowel bars or reinforcement cannot be used due to the way it is consolidated. These shorten the pavement life and increase the cost of maintenance. Therefore in order to reduce these defects by reducing the pavement deterioration and improving its service life, one of the possible ways is by incorporating additives such as polymers, fibers or crumb rubber (CR) into the RCC mix where it will absorb the deformation and strain energy caused by the repetitive loadings. The aim of this study was to improve the flexural strength, flexural toughness and ductility of RCC pavement. CR was used to partially replace fine aggregate at different percentages $(0 \%, 10 \%, 20 \%$ and $30 \%)$ to produce roller compacted rubbercrete (RCR), and nano silica (NS) was added by weight of cementitious materials at $0 \%, 1 \%, 2 \%$ and $3 \%$ to mitigate loss in strength caused by CR. The findings showed that both flexural toughness and ductility index of RCC increases with increasing CR content. Similarly, the flexural strength of RCR increases for up to $20 \%$ replacement of fine aggregate with CR. The addition of NS increases the flexural strength of RCR; however it decreases toughness and ductility index, thereby making the RCR more rigid. Lastly response surface methodology (RSM) analysis was used to develop model for predicting the flexural toughness and ductility index of RCR using CR and NS as the variables. The analysis of variance (ANOVA) showed that the developed models have a good degree of correlation and predicting ability.
\end{abstract}

(C) 2017 The Authors. Published by IASE. This is an open access article under the CC BY-NC-ND license (http://creativecommons.org/licenses/by-nc-nd/4.0/).

\section{Introduction}

Roller compacted concrete (RCC) is defined as a zero slump dry concrete with consistency enabling cast and compact it using highway construction equipment (ACI, 2011) The major differences between RCC and conventional concrete include; higher compaction effort, lower cementitious materials content, higher fine aggregate content, lower paste content, different aggregate grading and less entrain air (Mehta and Monteiro, 2006). RCC is used for dams and pavement applications due to its multiple advantages in comparison with normal concrete, these advantages include lower construction cost, rapid construction process, and lower cement content, early load carrying capacity,

\footnotetext{
* Corresponding Author.

Email Address: musa.adamu_g03310@utp.edu.my (M. Adamu) https://doi.org/10.21833/ijaas.2017.09.002

2313-626X/C) 2017 The Authors. Published by IASE.

This is an open access article under the CC BY-NC-ND license

(http://creativecommons.org/licenses/by-nc-nd/4.0/)
}

higher durability and lower maintenance cost (Mehta and Monteiro, 2006). In pavement application, RCC is subjected to repetitive fatigue loads and flexural stresses. These stresses shorten the pavement lifespan and increase the maintenance cost (Adamu et al., 2016). Therefore, to reduce these effects by preventing pavement deterioration and improving its service life, crumb rubber (CR) has been introduced into the RCC mixture to form roller compacted rubbercrete (RCR). CR particles in RCR, due to its nature, has the ability to absorb the deformation and strain energy caused by the repetitive loadings (Sengoz and Topal, 2005; Moghaddam et al., 2011).

However, CR has a hydrophobic nature which makes it repel water and entrap air on its surface, this leads to less bonding between CR particles and the hardened cementitious paste (Mohammed et al., 2011). Therefore, using CR as a partial replacement to fine aggregate will lead to a reduction in the modulus of elasticity and strengths of rubbercrete (Youssf et al., 2016; Mohammed and Azmi, 2014). 
The hydrophobic nature of CR particles can also be attributed to the presence of zinc stearate during the production of the tire which consequently diffuses to the rubber surface during mixing in concrete making the CR to entrap air and repel water (Youssf et al., 2014).

This result in the higher amount of air content inside the fresh mix thus leading to increased void content and porosity in the hardened rubbercrete thereby reduces its durability performance and strengths (Mohammed et al., 2012; Azmi et al., 2008, Mohammed et al., 2016). Several attempts to mitigate loss of strength in rubbercrete, but the method that proves to be more effective and economical is the use of nano silica in small amount as addition to cement which will help in refining the pore system, densification of the interfacial transition zone, refining the microstructure and reacting with available $\mathrm{Ca}(\mathrm{OH})_{2}$ to produce more C$\mathrm{S}-\mathrm{H}$ gel leading to improved strength in rubbercrete (Mohammed et al., 2016).

However, in comparison to conventional concrete, utilizing CR into concrete as a partial replacement for the fine aggregate lead to improving several properties of the rubbercrete such as; higher ductility and higher energy absorption (Ahoor and Zandi-Atashbar, 2014). Therefore, rubbercrete has been used to produce highway safety crush barrier (Atahan and Yucel, 2012).

Al-Tayeb et al. (2013) reported an increase in energy absorption capacity by $10.05 \%, 24.51 \%$, and $29.41 \%$ when they partially replaced fine aggregate with $5 \%, 10 \%$, and $15 \%$ CR respectively in rubbercrete. Grdic et al. (2014) also reported an increase in ductility of rubbercrete by $25 \%, 81.25 \%$, and $93.73 \%$ when fine aggregate was partially replaced with $10 \%, 20 \%$, and $30 \%$ CR respectively. Similarly, (Atahan and Yucel, 2012) replaced up to $100 \%$ fine aggregate with crumb rubber in rubbercrete, and the energy absorption to increase by $90.8 \%, 112.7 \%, 141.5 \%, 165.6 \%$, and $160.8 \%$ for $20 \%, 40 \%, 60 \%, 80 \%$ and $100 \%$ CR respectively.

According to Zheng et al. (2008) replacing fine aggregate with $15 \%, 30 \%$, and $45 \%$ CR in rubberized concrete decreases its brittleness index by $45.2 \%$, $52.22 \%$, and $54.1 \%$ respectively. Ozbay et al. (2011) partially replaced fine aggregate with CR at levels $5 \%, 15 \%$ and $25 \%$ by volume in rubbercrete; they reported an increase in energy absorption by $2.2 \%$, $10.9 \%$, and $24.6 \%$ respectively.

Moustafa and ElGawady (2015) reported an increase in damping ratio in rubbercrete by $5.3 \%$, $19.8 \%$, and $22.9 \%$ when fine aggregate is replaced with $10 \%, 20 \%$, and $30 \%$ crumb rubber respectively. Mohammed (2010) also reported improved ductility when CR partially replaced up to $10 \%$ fine aggregate in composited slabs. In summary, it is worthwhile mentioning that partial replacement of fine aggregate with CR in concrete increases its ductility and energy absorption capacity.

RCC pavement is a mass concrete application and due to the way it is placed and compacted, dowel bars, tie rods or steel reinforcement cannot be used
(Adaska, 2006). RCC pavement is subjected to fatigue loadings from traffic, thus causing tension, bending stresses, and fatigue cracking. These affect the pavement performance and shorten its design life (Mansour and Ershad, 2017).

Therefore to reduce these effects, additives such as polymers, fibers or CR can be incorporated into the RCC pavement where it will absorb the deformation and strain energy caused by the traffic loads (Moghaddam et al., 2011).

In this study, CR was used as a partial replacement to fine aggregate to improve the ductile behavior and energy absorption capacity of RCC pavement. Nano silica was added by weight of cementitious materials to mitigate the loss of strengths in RCC pavement due to the incorporation of CR.

\section{Materials and methods}

\subsection{Materials}

The materials used in this study are cementing, sand, coarse aggregate, fly ash and nano silica. The cement is Type I Portland cement has a specific gravity of 3.15 and conforms to the requirements of ASTM C150M-15. The sand is natural river sand with a maximum size of $4.75 \mathrm{~mm}$ and has a specific gravity of 2.65 , water absorption $1.24 \%$ and fineness modulus 2.86 .

Two nominal maximum size aggregates (NMSA) have been used, which are19 $\mathrm{mm}$ (3/4 Inch) with specific gravity and water absorption of 2.66 and $0.48 \%$, respectively, and $6.35 \mathrm{~mm}(1 / 4$ inch) with specific gravity and water absorption of 2.55 and $1.05 \%$, respectively. Three sizes of crumb rubber have been blended to achieve gradation similar to that of fine aggregate. After several series of trial combinations, using sieve analysis according to ASTM D5644, final proportion of $40 \%$ of $0.595 \mathrm{~mm}$, $40 \%$ of $1-3 \mathrm{~mm}$, and $20 \%$ of $3-5 \mathrm{~mm}$ has been used. The particles size distribution of crumb rubber and aggregates used is shown in Fig. 1.

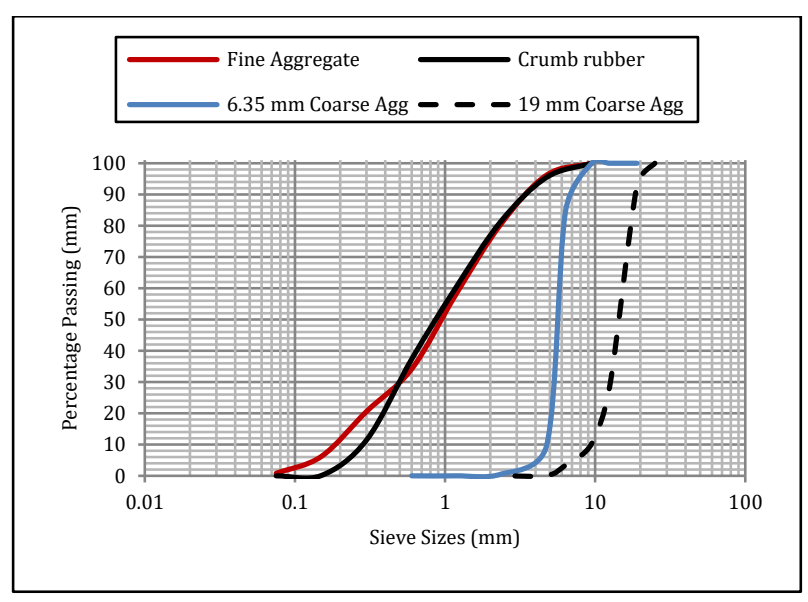

Fig. 1: Grading of aggregate

One of the requirements for RCC pavement production is using materials finer than $75 \mu \mathrm{m}$ (No 
200) sieve to achieve a more cohesive paste with reduced void volume, and the recommended amount should be between $2 \%$ to $8 \%$ of the aggregate (CRDC, 1992), therefore class F Fly ash conforms to ASTM C612 and ASTM C311 has been used as mineral filler (Adamu et al., 2017). Nano silica with size $10-25$ $\mathrm{nm}$ has been used as an addition to cementitious materials. The chemical compositions of cement, fly ash and nano silica is shown in Table 1.

Table 1: Materials properties

\begin{tabular}{cccc}
\hline Oxides composition (\%) & Cement & Fly ash & Nano silica \\
\hline $\mathrm{SiO}_{2}$ & 20.76 & 57.06 & 99.8 \\
$\mathrm{Al}_{2} \mathrm{O}_{3}$ & 5.54 & 20.96 & - \\
$\mathrm{Fe}_{2} \mathrm{O}_{3}$ & 3.35 & 4.15 & - \\
$\mathrm{MnO}$ & - & 0.033 & - \\
$\mathrm{CaO}$ & 61.4 & 9.79 & - \\
$\mathrm{MgO}$ & 2.48 & 1.75 & - \\
$\mathrm{Na} O$ & 0.19 & 2.23 & - \\
$\mathrm{K}_{2} \mathrm{O}$ & 0.78 & 1.53 & - \\
$\mathrm{TiO}_{2}$ & - & 0.68 & - \\
Loss of ignition & 2.2 & 1.25 & - \\
Specific gravity & 3.15 & 2.3 & - \\
Blaine fineness $\left(\mathrm{m}^{2} / \mathrm{g}\right)$ & 0.325 & 0.290 & $100 \pm 25$ \\
\hline
\end{tabular}

\subsection{Mix proportioning}

Mix proportioning has been carried out in accordance with the requirements of geotechnical approach to ACI (2002). The first step is to obtain a combined grading of fine and coarse aggregate to be within the maximum and minimum limits of the gradation curve based on requirements of US Army corps of Engineers method (CRD-C, 1992).

Fig. 2 shows the combined aggregate gradation curve and it has been obtained by combining $55 \%$ of fine aggregate, $20 \%$ of $19 \mathrm{~mm}$ maximum size coarse aggregate, $20 \%$ of $10 \mathrm{~mm}$ maximum size coarse aggregate, and $5 \%$ fly ash as a mineral filler.

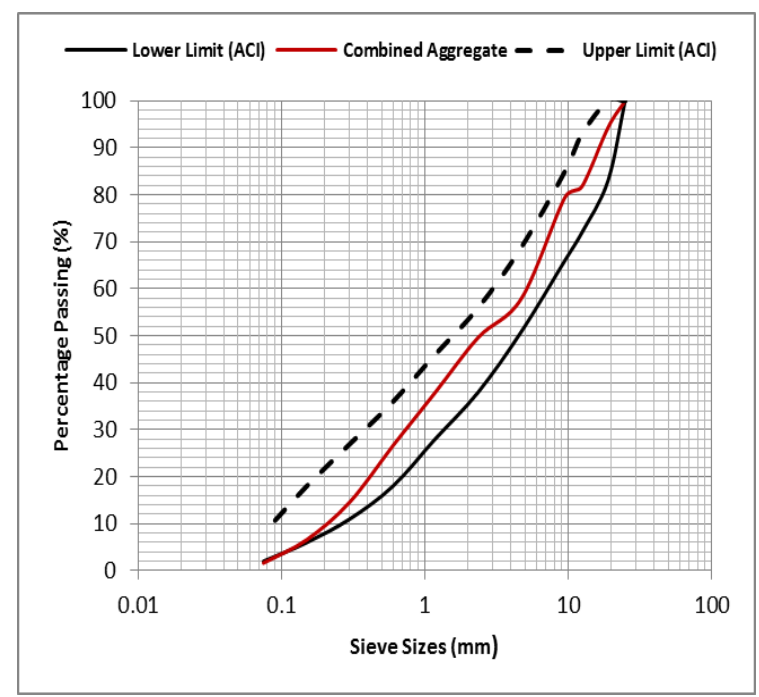

Fig. 2: Combined aggregate grading

Next is to determine the optimum water content of the mix in accordance with the requirements of ASTM D 1557-12e. Cement content of $12 \%, 13 \%$, and $15 \%$ by weight of dry aggregate and water content varies from $4.5 \%$ to $6.5 \%$ for each cement content, to obtain a plot of moisture content against dry density, have been selected. The optimum moisture content
(OMC) for $12 \%, 13 \%, 14 \%$ and $15 \%$ has been found to be $5.46 \%, 5.56 \%, 5.92 \%$ and $6.09 \%$, respectively. Four RCC mixes have been prepared with 12\%, 13\%, $14 \%$ and $15 \%$ cement content and water content equal to their OMC and then have been tested for compressive strength and flexural strengths at 28 days to establish the relationship between cement content and compressive/flexural strength as shown in Fig. 3.

From Fig. 3, 13\% cement content has been selected based on the target flexural strength of 4.3 $\mathrm{MPa}$ (C30/37MPa compressive strength). A water/cement ratio of 0.42 has been chosen based on the quantities of selected materials. To increase the consistency of the mix and reduce the water content, $1 \%$, by weight of cement, superplasticizer has been added and the water content has been reduced by $12 \%$, bringing the water/cement ratio down to 0.37 .

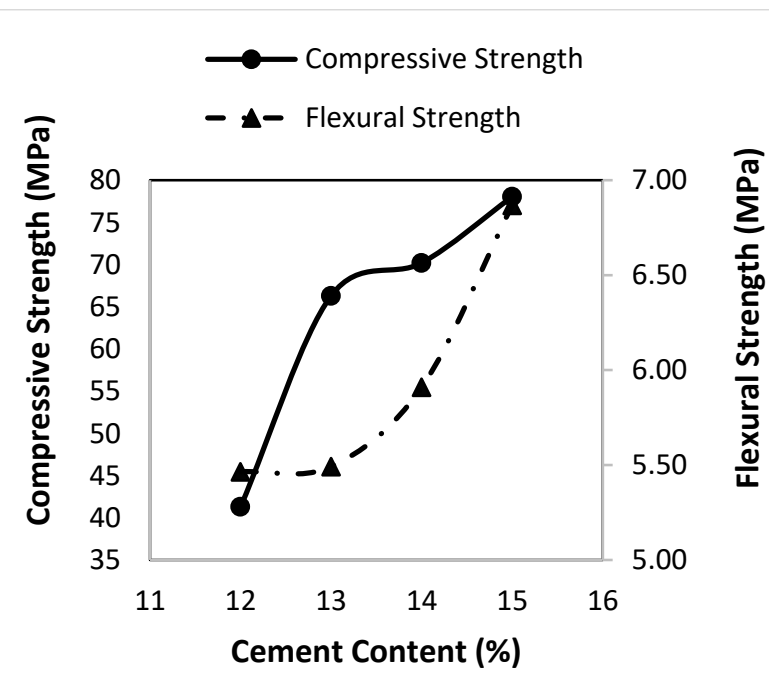

Fig. 3: Relationship between cement content and strength

\subsection{Sample preparation and testing}

In order to study the effects of nano silica (NS) addition on flexural performance of roller compacted rubbercrete (RCR), sixteen mixes have been prepared by partially replacing fine aggregate with crumb rubber (CR) at $0 \%, 10 \%, 20 \% 30 \%$ replacement level by volume, and addition of $1 \%$, $2 \%$ and $3 \%$ NS by weight of cement. Each mix is given a designation based on the percentage of CR and NS, for example, MOCON refers to RCR mix with $0 \%$ of CR and $0 \%$ of NS (control mix), while M30C3N is a mix with $30 \%$ of $\mathrm{CR}$ and $3 \%$ of NS. Mix proportions are shown in Table 2.

Adequate vibration for RCC mix for pavement applications is required to avoid and honeycombs in the hardened mix and to resemble more the real case, specially made vibration hammer of $50 \mathrm{~Hz}$ capacity together with a shaft connecting the hammer and the base plates of $10 \mathrm{~mm}$ thickness were produced.

Flexural strength has been determined according to the requirements of ASTM C293M-10 whereas 
nine beams with the size of $100 \mathrm{~mm} \times 100 \mathrm{~mm} \times 500$ $\mathrm{mm}$ have been produced for each mix and tested at age of 7, 28 and 90 days of curing. The flexural toughness is calculated by measuring the area under the load-deflection curve (ACI, 1999), while the ductility index $\mu \mathrm{D}$ is calculated using Eq.1 (Grdic et al., 2014)

$\mu D=\frac{\Delta U}{\Delta Y}$,

where $\mu \mathrm{D}$ is the ductility index, $\Delta \mathrm{U}$ is the mid-span deflection at the ultimate load in $\mathrm{mm}$ and $\Delta \mathrm{Y}$ is the mid-span at yield (first crack).

\section{Results and discussions}

\subsection{Flexural strength}

Flexural strength is the most important material property for the design of pavement (ERMCO, 2013). The flexural strength for all RCR mixes at age of 7, 28, and 90 days are presented in Fig. 4. It was found that the 28 days flexural strength of RCR mixes increases by $39.3 \%, 9.3 \%$ and $2.2 \%$ when the fine aggregate is replaced with $10 \%, 20 \%$, and $30 \% \mathrm{CR}$, respectively. These results are in agreement with the findings of Yilmaz and Degirmenci (2009).

Table 2: RCR mix proportions

\begin{tabular}{|c|c|c|c|c|c|c|c|c|}
\hline \multirow{2}{*}{ Mixture } & \multicolumn{8}{|c|}{ Quantities for $1 \mathrm{~kg} / \mathrm{m}^{3}$ of RCR } \\
\hline & Cement & Nano silica & Filler & Fine aggregate & Coarse aggregate $19 \mathrm{~mm}$ & Coarse aggregate $10 \mathrm{~mm}$ & Water & CR \\
\hline MOCON & 268.69 & 0 & 103.76 & 1148.05 & 415.03 & 416.85 & 98.24 & 0 \\
\hline M0C1N & 268.69 & 2.69 & 103.76 & 1148.05 & 415.03 & 416.85 & 98.24 & 0 \\
\hline M0C2N & 268.69 & 5.37 & 103.76 & 1148.05 & 415.03 & 416.85 & 98.24 & 0 \\
\hline M0C3N & 268.69 & 8.06 & 103.76 & 1148.05 & 415.03 & 416.85 & 98.24 & 0 \\
\hline $\mathrm{M} 10 \mathrm{C} 0 \mathrm{~N}$ & 268.69 & 0 & 103.76 & 1033.25 & 415.03 & 416.85 & 98.24 & 114.89 \\
\hline M10C1N & 268.69 & 2.69 & 103.76 & 1033.25 & 415.03 & 416.85 & 98.24 & 114.89 \\
\hline M10C2N & 268.69 & 5.37 & 103.76 & 1033.25 & 415.03 & 416.85 & 98.24 & 114.89 \\
\hline M10C3N & 268.69 & 8.06 & 103.76 & 1033.25 & 415.03 & 416.85 & 98.24 & 114.89 \\
\hline $\mathrm{M} 20 \mathrm{C} 0 \mathrm{~N}$ & 268.69 & 0 & 103.76 & 918.44 & 415.03 & 416.85 & 98.24 & 229.78 \\
\hline M20C1N & 268.69 & 2.69 & 103.76 & 918.44 & 415.03 & 416.85 & 98.24 & 229.78 \\
\hline M20C2N & 268.69 & 5.37 & 103.76 & 918.44 & 415.03 & 416.85 & 98.24 & 229.78 \\
\hline M20C3N & 268.69 & 8.06 & 103.76 & 918.44 & 415.03 & 416.85 & 98.24 & 229.78 \\
\hline M30C0N & 268.69 & 0 & 103.76 & 803.64 & 415.03 & 416.85 & 98.24 & 344.67 \\
\hline M30C1N & 268.69 & 2.69 & 103.76 & 803.64 & 415.03 & 416.85 & 98.24 & 344.67 \\
\hline M30C $2 N$ & 268.69 & 5.37 & 103.76 & 803.64 & 415.03 & 416.85 & 98.24 & 344.67 \\
\hline M30C3N & 268.69 & 8.06 & 103.76 & 803.64 & 415.03 & 416.85 & 98.24 & 344.67 \\
\hline
\end{tabular}

The increase in flexural strength is attributed to the high bending deformation and fiber nature of CR, which gives the RCR post-cracking behavior and allows it to resist some flexural load even after failure (Thomas and Gupta, 2015). For all the mixes, high flexural strength values of more than $4 \mathrm{MPa}$ was achieved due to the high compaction applied in combination with the low water to cement ratio of RCR (Fakhri, 2016).

The addition of $1 \%$ NS has led to increasing the flexural strength for all CR percentages, which are in good agreement with findings reported by Mohammed et al. (2016), but beyond 1\%, some mixes exhibit a reduction in flexural strength while others show improvement as shown in Fig. 4. The increasing in the flexural strength of RCR with addition of NS is attributed to the following reasons; NS fills the pore structures of RCR up to nano size making the hardened RCR mix denser, high pozzolanic reaction of NS making it react and consume the surplus Portlandites $(\mathrm{Ca}(\mathrm{OH}) 2)$ produced during hydration process in the concrete producing more calcium-silicate-hydrate (C-S-H) gel which is the main compound for strength development and densification of the interfacial transition zone between CR and NS (Mukharjee and Barai, 2014).

While the decrease in flexural strength with higher NS is attributed to the agglomeration of nanoparticles which adversely affect the microstructure of the hardened cement paste (Mohammed, 2015).

\subsection{Flexural toughness and energy absorption}

The major advantage of using crumb rubber in rubbercrete is to improve its ductility and delay crack initiation time (Siddique, 2007). The ductility of RCR with $0 \%, 1 \%, 2 \%$ and $3 \%$ of NS are measured by plotting the load deflection curve obtained from measuring the bending resistance as shown in Fig $5 a-5 d$.

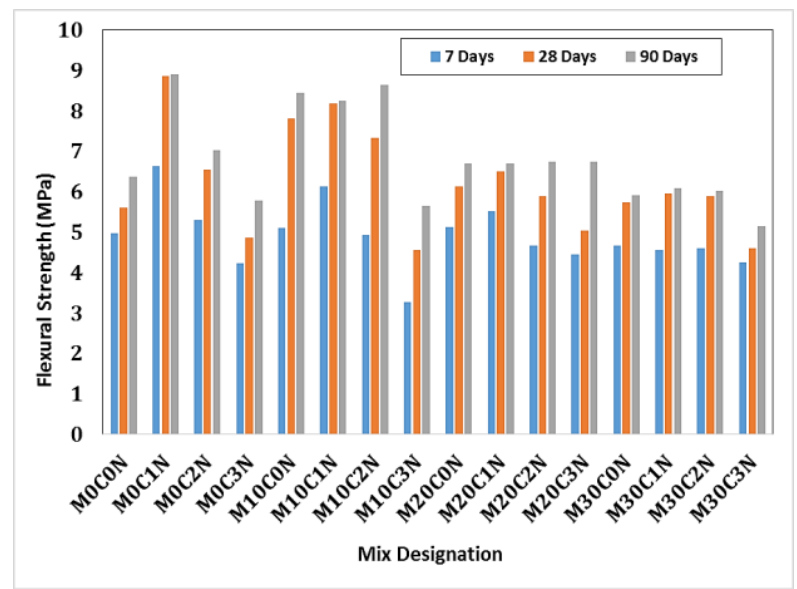

Fig. 4: Flexural strength of RCR

While their toughness is obtained by calculating the area under the load-deflection curves as shown in Table 3. 


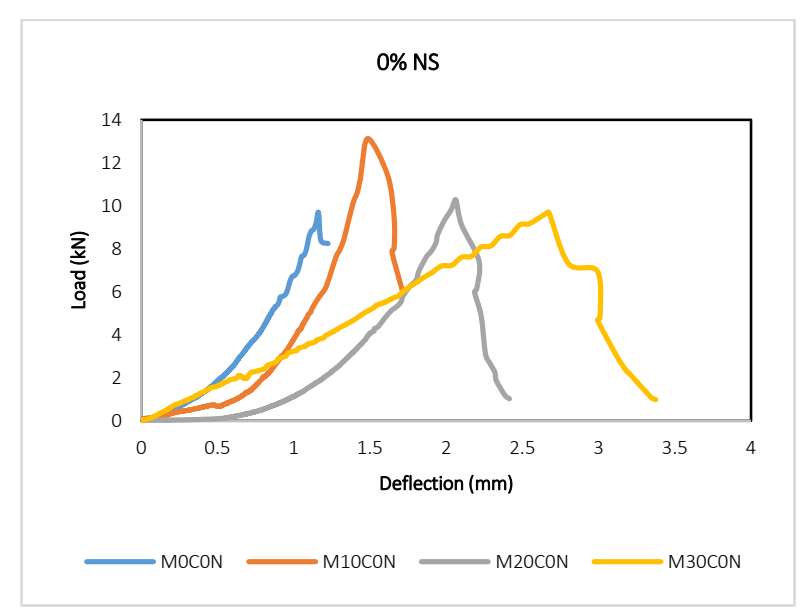

(a)

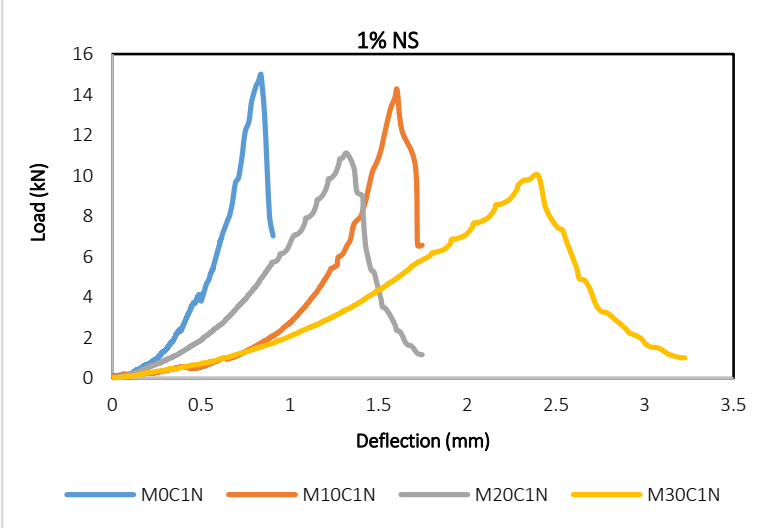

(b)

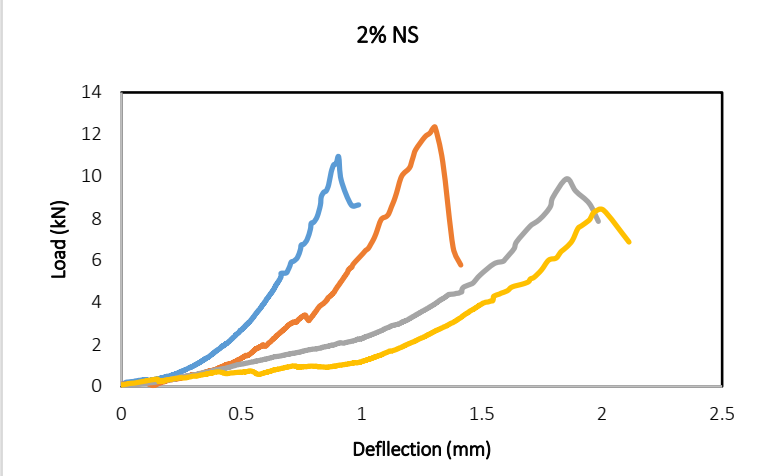

MOC2N $=$ M10C2N M20C2N $=$ M30C2N

(c)

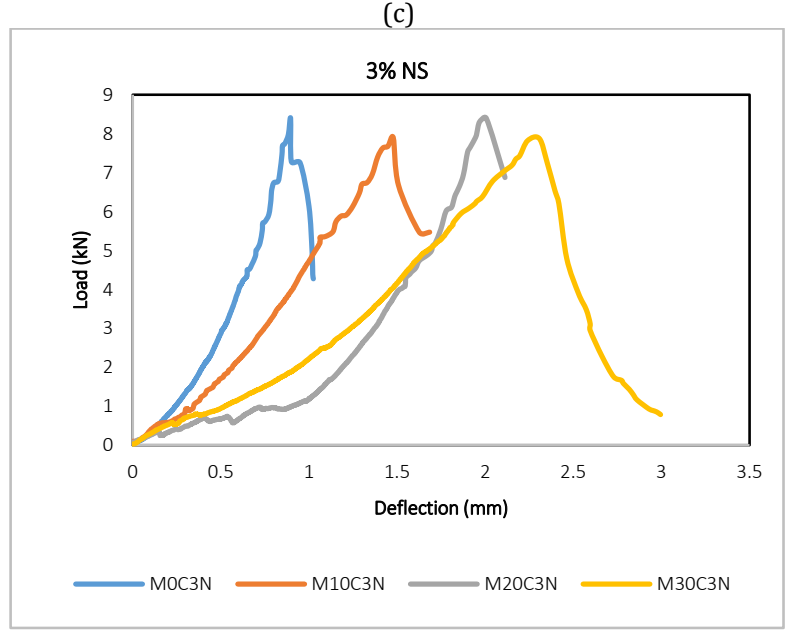

(d)

Fig. 5: Load-deflection curve a) for RCR with $0 \%$ NS b) RCR with $1 \%$ NS c) RCR with $2 \%$ NS d) RCR with $3 \%$ NS
Deflection at ultimate load and a breaking point increase with an increase in partial replacement of fine aggregate with crumb rubber. Also higher crumb rubber replacement level shows a more ductile behavior considering the load-deflection (curve) gradient.

At the ascending side of the curve, the slope of $0 \%$ CR is the steepest while that of $30 \%$ CR is the mildest. This implies that RCR can withstand continues loading for a longer duration without failure by delaying crack initiation time. Similarly, after attaining peak load, the post-cracking behavior increases with increment in crumb rubber content as shown from the descending side of the loaddeflection curves as shown in Fig. 5a. Where the curves of $30 \%$ and $20 \%$ of CR descending gradually after failure without breaking until the applied load descend towards zero compared to $0 \%$ and $10 \%$ CR which suddenly breaks up after attaining maximum bending resistance as shown in Fig. 5a. The energy absorption of RCR can be obtained by measuring its toughness which is the area under the loaddeflection curve. As shown in Table 3, the toughness of RCR increases with increasing crumb rubber content. The increase in ductile behavior and toughness of RCR with an increase in crumb rubber is attributed to low stiffness and high deformation of CR particles which can be easily bent or twist which gives the RCR more flexible behavior than the conventional RCC thus making it absorb more energy (Ozbay et al., 2011). Therefore RCR can be good material for pavement application subjected to repetitive cycles of loading from traffic as it will delay fatigue cracks initiation and propagation. The effect of NS addition on the ductility of RCR is shown in Fig $6 b-6 d$, it can be seen that addition of NS increases the bending strength resistance but decreases deflection and ductility. The increase in peak load is attributed to the ability of NS in pore filling, densifying the interfacial transition zone (ITZ) and production of more C-S-H gel which is responsible for strength. While the decrease in peak load for higher NS percentage (3\%) might be due to agglomeration of NS (Mohammed et al., 2016). On the other hand, NS addition decreases both the maximum deflection and toughness as shown in Table 3.

Addition of $2 \%$ NS decreases the maximum deflection of RCR containing 10\%, 20\% and $30 \%$ of CR by $17.6 \%, 17.8 \%$ and $9.3 \%$, respectively. While toughness decreases by $4.4 \%, 11.1 \%$, and $12.8 \%$ for $10 \%, 20 \%$ and $30 \%$ of $\mathrm{CR}$, respectively. Also as shown from the load-deflection (curves) NS reduces the ductile behavior gained by RCR due to partial replacement of fine aggregate with crumb rubber, this can be seen by observing the slopes of the curves of mixes containing NS as they become steeper at the ascending part, and towards the descending end they breaks immediately after attaining ultimate load. Therefore NS decreases crack initiation time and reduces the post-cracking behavior with failure occurring catastrophically rather than slowly thus making RCR more brittle. 
This reduction in ductility of RCR with NS addition is attributed to the higher stiffness and modulus of elasticity which is directly proportional to brittleness. NS refine the microstructure and densify the ITZ of RCR, thus increasing its stiffness and modulus of elasticity (Mohammed et al., 2016).

\subsection{Ductility index}

The ductility index of RCR for different nano silica (NS) contents is shown in Fig. 6. The ductility index is used to measure how ductile or brittle the RCR as the brittleness of concrete is inversely proportional to its ductility.

As shown in Table 3 and Fig. 7, replacement of fine aggregate with crumb rubber (CR) increases the ductile behavior of RCR which is similar to the findings reported by Hilal (2017) for self-compacting concrete. The ductility index of RCR increases by $10.63 \%, 12.63 \%$ and $34.9 \%$ for $10 \%, 20 \%$ and $30 \%$ of CR contents, respectively. This increasing is mainly due to low stiffness, high elastic and deformation of CR particles which gives it the ability to resist bending twisting, compression, bridge cracks, and absorb energy (Liu et al., 2015, Kardos and Durham, 2015). The addition of NS increases the flexural strength of RCR. However, it makes RCR more brittle and rigid by decreasing the ductility index as shown in Fig. 6 and Table 3. This is due to the microstructural refinement through pore filling ability and the pozzolanic reaction of NS, thus increasing the elastic modulus and reducing the flexibility of RCR and consequently reducing its energy absorption and ductile behavior (Mohammed et al., 2016, Amin and Abu el-Hassan, 2015).

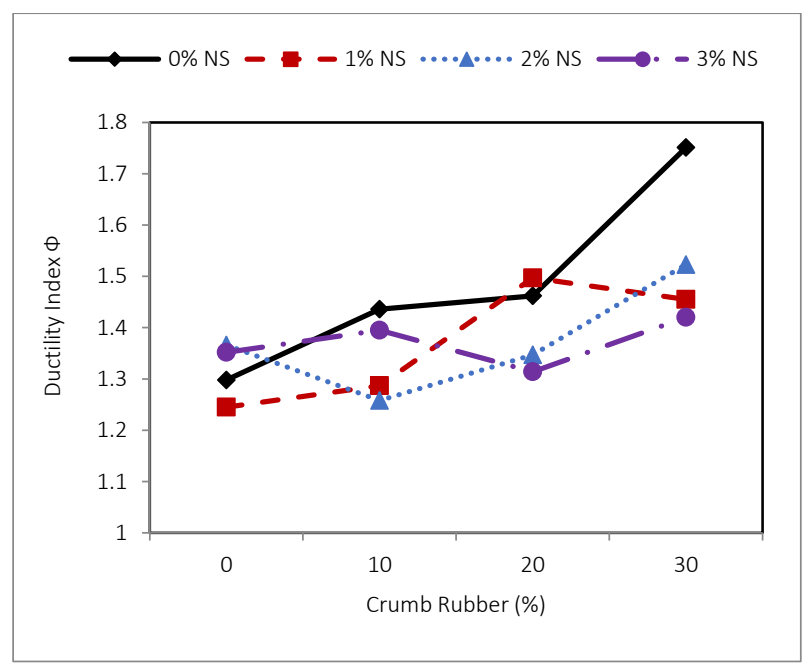

Fig. 6: Ductility index for RCR

Table 3: Flexural toughness and ductility index of RCR

\begin{tabular}{ccccc}
\hline Mix & Max Load $(\mathrm{kN})$ & Max Deflection $(\mathrm{mm})$ & Toughness $(\mathrm{kN} . \mathrm{mm})$ & Ductility Index \\
\hline M0C0N & 9.68 & 1.23 & 4.23 & 1.30 \\
M0C1N & 14.99 & 0.91 & 4.48 & 1.25 \\
M0C2N & 10.93 & 0.99 & 3.72 & 1.37 \\
M0C3N & 8.39 & 1.03 & 3.51 & 1.35 \\
M10C0N & 13.13 & 1.72 & 7.14 & 1.44 \\
M10C1N & 14.24 & 1.75 & 6.67 & 1.29 \\
M10C2N & 12.35 & 1.41 & 5.76 & 1.26 \\
M10C3N & 7.90 & 1.69 & 6.19 & 1.40 \\
M20C0N & 10.26 & 2.42 & 7.03 & 1.46 \\
M20C1N & 11.10 & 1.75 & 7.23 & 1.50 \\
M20C2N & 9.89 & 1.99 & 6.65 & 1.35 \\
M20C3N & 8.40 & 2.11 & 5.64 & 1.31 \\
M30C0N & 9.68 & 3.38 & 15.85 & 1.75 \\
M30C1N & 9.99 & 3.23 & 11.91 & 1.46 \\
M30C2N & 10.51 & 2.81 & 13.39 & 1.52 \\
M30C3N & 7.88 & 2.99 & 9.70 & 1.42 \\
\hline
\end{tabular}

\subsection{Relationship between flexural toughness and} mechanical properties of RCR

3.4.1. Relationship between maximum load, deflection, and flexural toughness

The flexural toughness (energy absorption capacity) of RCR is calculated by measuring the area under the load-deflection curve. This is done either by using Microsoft excel or mathematical integration which can be tedious to compute with many errors. Therefore, in this research, the model was developed using multivariable regression and presented in Eq. 2 to calculate the flexural toughness of RCR using the maximum load and maximum deflections as the variables.

$\Delta=1.333 \times 1.051^{P} \times 1.752^{\alpha}$ where $\Delta$ is the flexural toughness in kN.mm, P is the load in $\mathrm{kN}$ and $\alpha$ is the deflection in $\mathrm{mm}$.

The adequacy of the developed model has been checked by using the result of ANOVA, the model has a high degree of determination $\left(\mathrm{R}^{2}=0.92\right)$ with the residual error of 0.13 . Therefore the developed model is in agreement with the experimental data. This can also be verified by plotting the predicted versus actual flexural toughness which is shown in Fig. 7. As seen the predicted model perfectly fitted the experimental data as all the data points fitted along the straight line.

\subsubsection{Relationship between flexural toughness and compressive/flexural strength}

The compressive strength and flexural strength are the two most important properties of for design of any RCC pavement (ERMCO, 2013). 


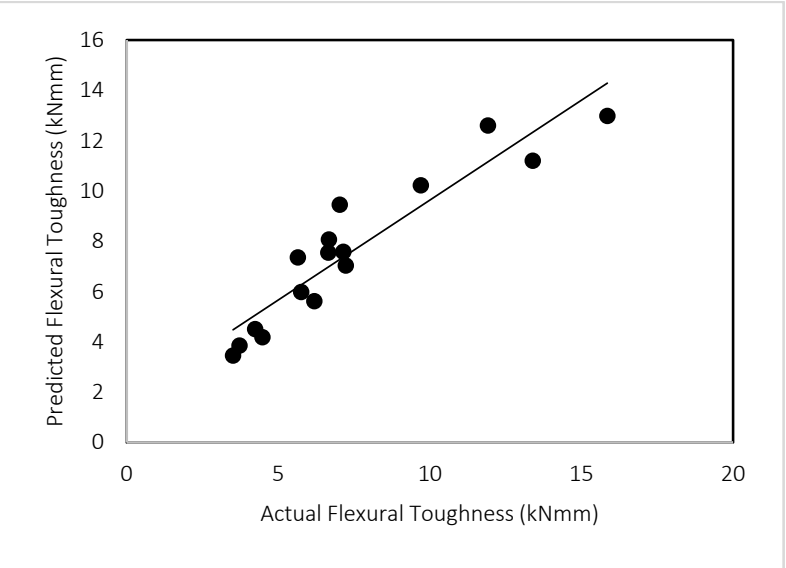

Fig. 7: Predicted versus actual toughness for RCR

Therefore, in this paper, the relationship between flexural toughness-compressive, ductility index- compressive strength, and ductility index-flexural strength have been developed using single variable regression analysis and the results are shown in Fig. 8, Fig. 9 and Fig. 10, respectively. While multivariable regression has been used to develop the relationship between flexural toughness versus compressive/flexural strengths, and ductility index versus compressive/flexural strength, the results are presented in Table 4. As seen in Fig. 8 there is a good correlation between flexural Toughness $(\Delta)$ and compressive strength (F), with $\mathrm{R}^{2}>0.9$ except for $1 \%$ NS RCR. While from Fig. 9 there is a very high degree of correlation between ductility index $(\Phi)$ of RCR and its compressive strength (FC) having $\mathrm{R}^{2}>0.9$ for all \% NS RCR models. Similarly, from Fig. 10, a good correlation between flexural strength (FM) and ductility index $(\Phi)$ of RCR was found having $\mathrm{R}^{2}>0.8$ for \% NS RCR models.

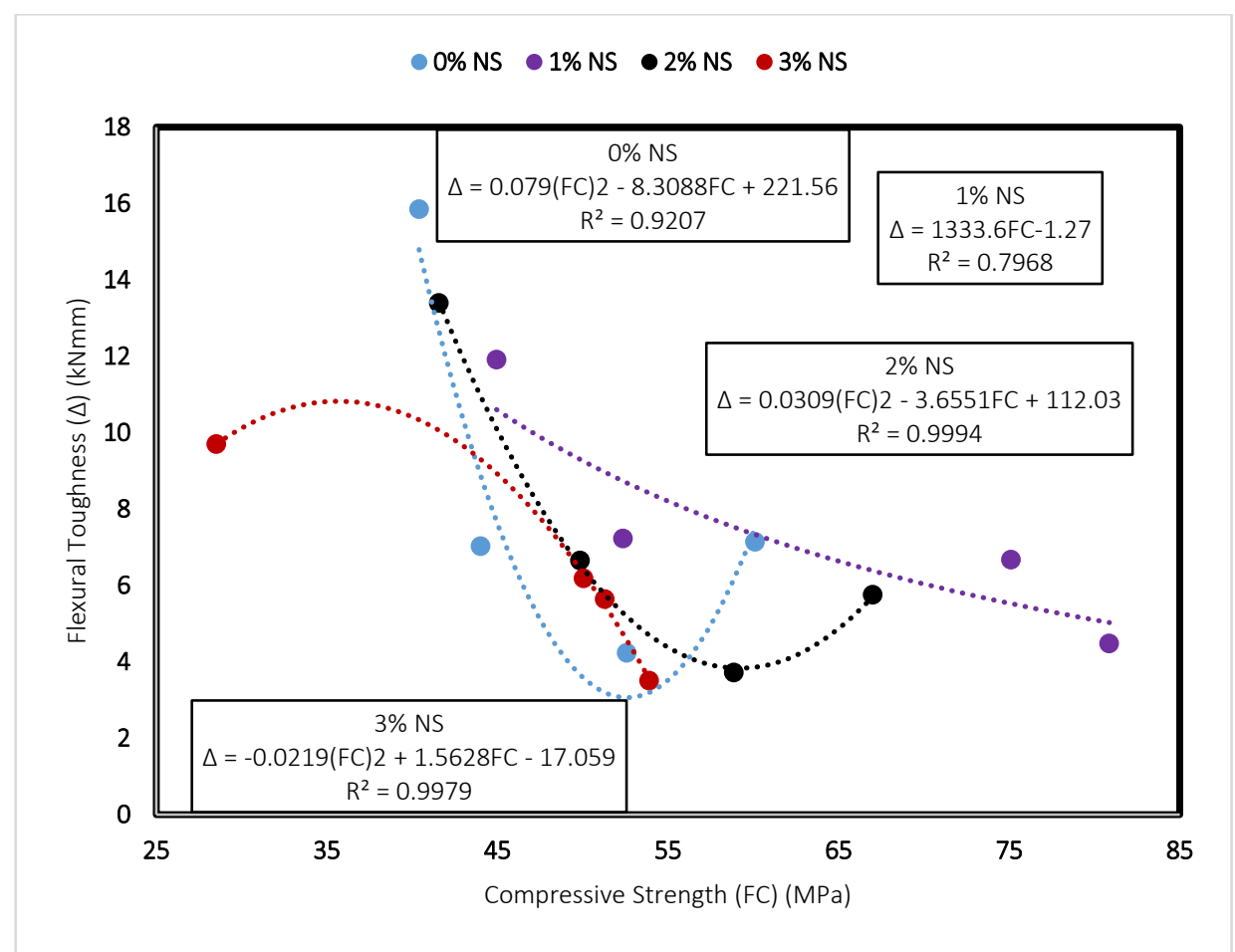

Fig. 8: Relationship between flexural toughness and compressive strength of RCR

As shown in Table 4 considering toughness, models for $2 \%$ NS and 3\% NS are multivariable linear models, while models for $0 \%$ NS and 1\% NS are double exponential and double power types, respectively. In addition, all the models have a high degree of determination (R2 > 0.8) except for $0 \%$ NS. While considering ductility index, all the models have a high degree of correlation expect model for $3 \%$ NS which has an unacceptable R2 $<0.5$. Therefore the developed multivariable models can be used to predict the flexural toughness and ductility index of RCR with different NS contents using its corresponding compressive strength and flexural strengths as the independent variables. However, ductility index for 3\% NS cannot be predicted using the multivariable regression.

The degree of correlation for each model is also measured graphically by plotting the predicted model against the actual experimental data as shown in Fig. 11a and Fig. 11b for toughness and Fig. 11c for ductility index. As seen all the data points fitted along the straight line meaning the predicted model is in agreement with the experimental data except model for 3\% NS ductility index which is not plotted.

\subsection{Response surface methodology}

The Response surface methodology (RSM) is the most suitable and commonly used statistical and mathematical technique used for analyzing and developing models between one or more independent variables and responses. In addition, RSM can be used for model multi-objective optimization by setting defined desirable goals based on either the responses or the variables. The response surface can be expressed mathematically by a single formulation as shown in Eq. 3 (Montgomery, 2008). 
$r=f\left(v_{1}, v_{2}\right)+\varepsilon$

where $\varepsilon$ is the observed error for the response R, $\mathrm{v}_{1}$ and $\mathrm{v}_{2}$ are the variables. The predictable response can be rewritten as $G(r)=f\left(v_{1}, v_{2}\right)=\beta$, where $\beta$ is the response surface.

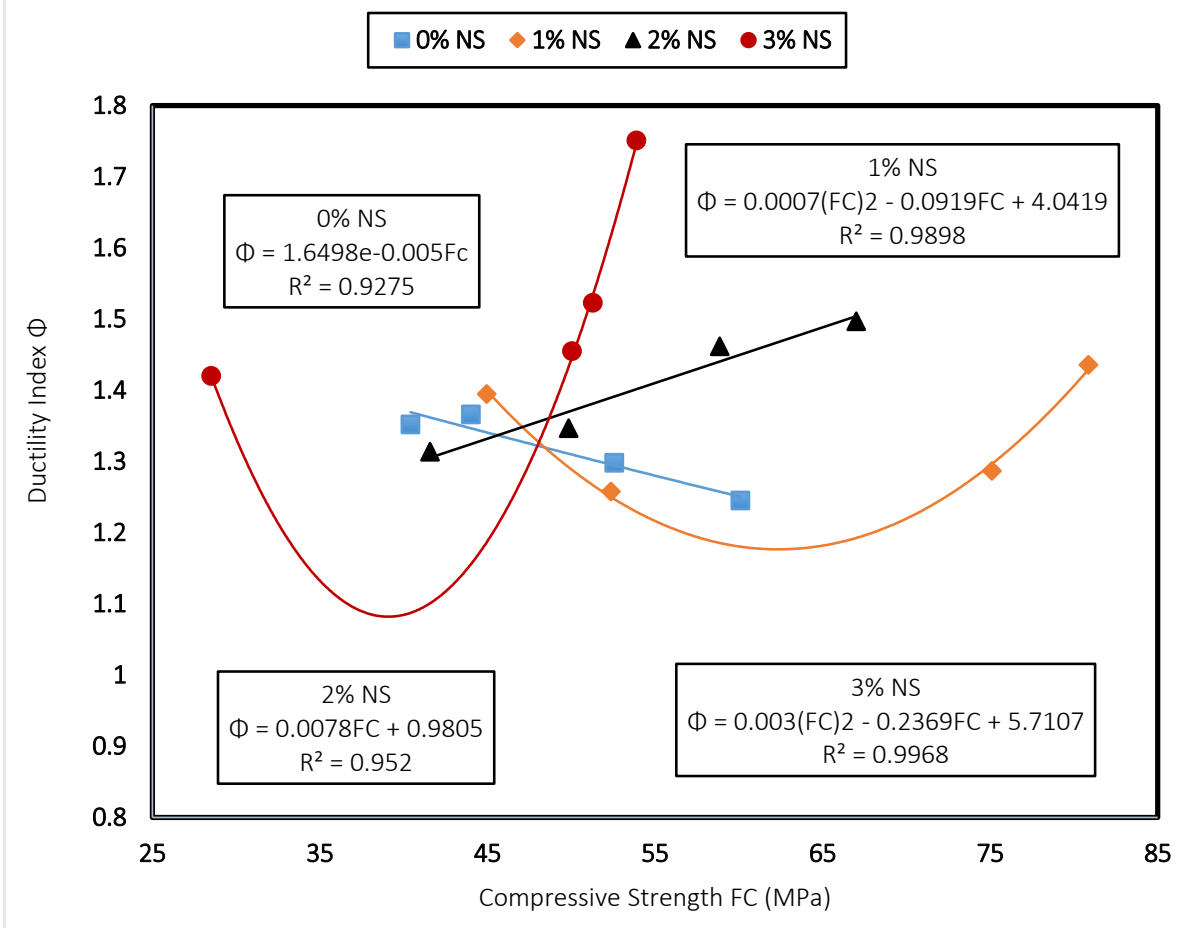

Fig. 9: Relationship between ductility index and compressive strength of RCR

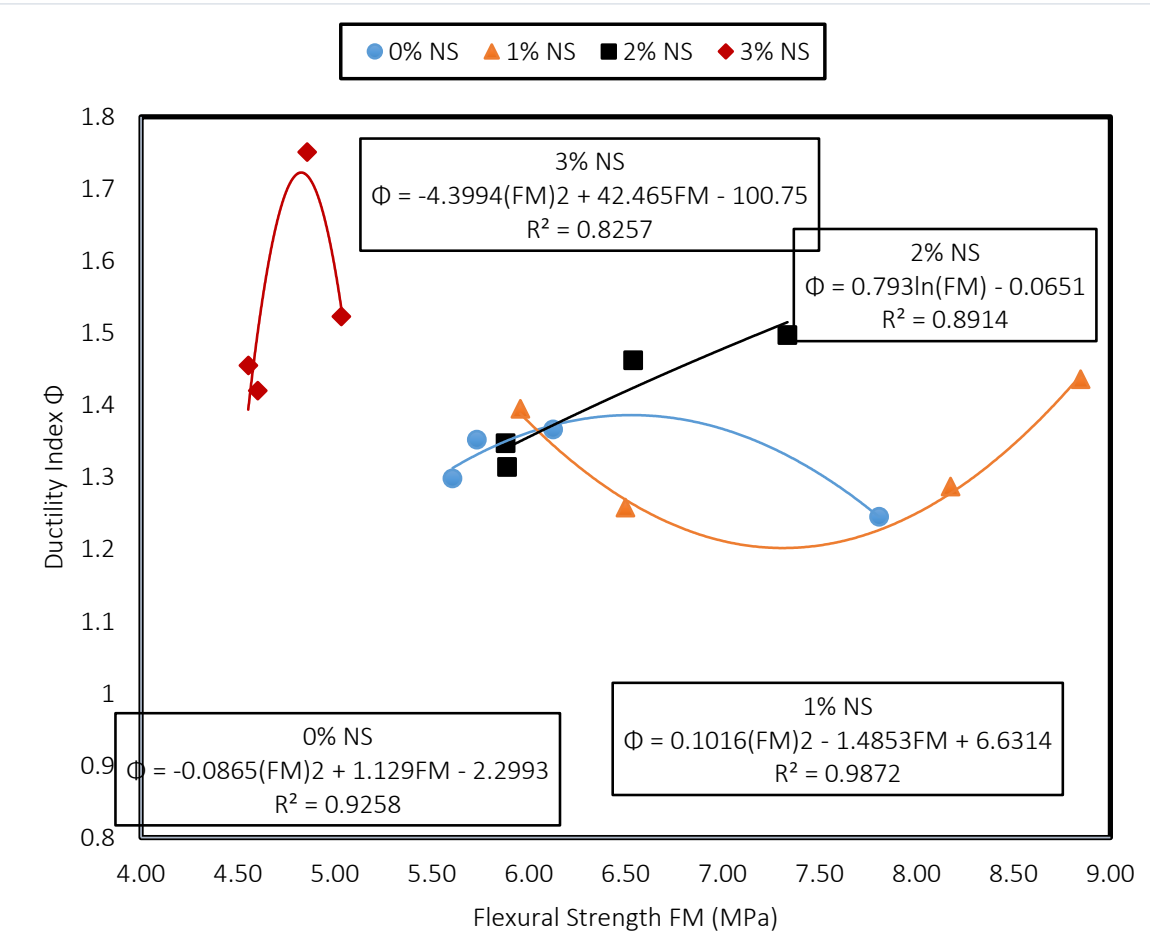

Fig. 10: Relationship between ductility index and flexural strength of RCR

Table 4: Models for predicting flexural toughness of RCR

\begin{tabular}{ccccc}
\hline Model & Toughness Models & $\mathrm{R}^{2}$ & Ductility Models & $\mathrm{R}^{2}$ \\
\hline $0 \%$ NS & $\Delta=6035506 \times F_{C}^{-3.6311} \times F_{M}^{2.979}$ & 0.723 & $\Phi=1.659 \times 0.996^{F_{C}} \times 0.997^{F_{M}}$ & 0.93 \\
$1 \% \mathrm{NS}$ & $\Delta=284.01 \times 1.0592^{F_{C}} \times 0.37^{F_{M}}$ & 0.835 & $\Phi=27.275 \times F_{C}^{-2.804} \times F_{M}^{4.303}$ & 0.87 \\
$2 \% \mathrm{NS}$ & $\Delta=-0.897 \times F_{C}+10.122 \times F_{M}-8.796$ & 0.974 & $\Phi=0.433 \times F_{C}^{0.206} \times F_{M}^{0.185}$ & 0.96 \\
$3 \% \mathrm{NS}$ & $\Delta=-0.198 \times F_{C}-0.96 \times F_{M}+19.909$ & 0.90 & $\Phi=0.742 \times 1.004^{F_{C}} \times 1.12^{F_{M}}$ & 0.48 \\
\hline
\end{tabular}




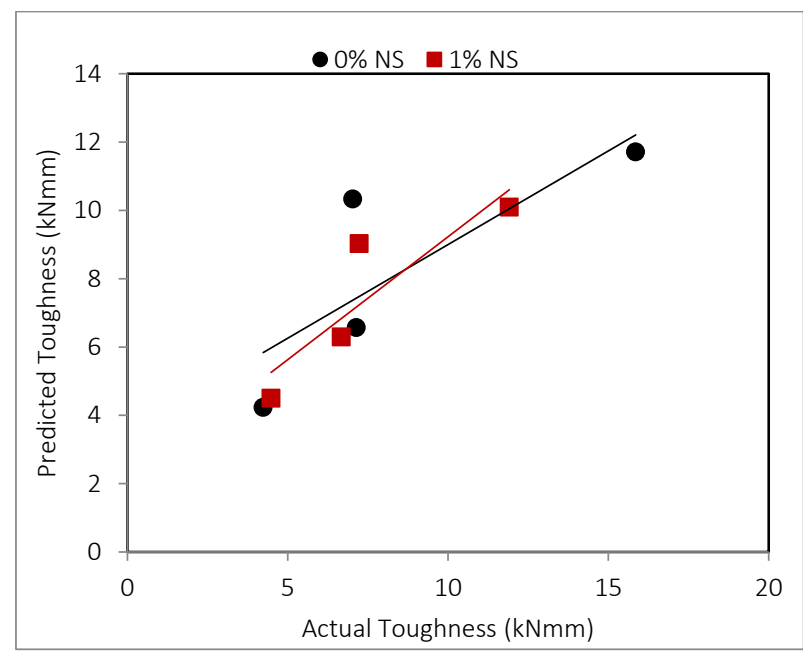

(a)

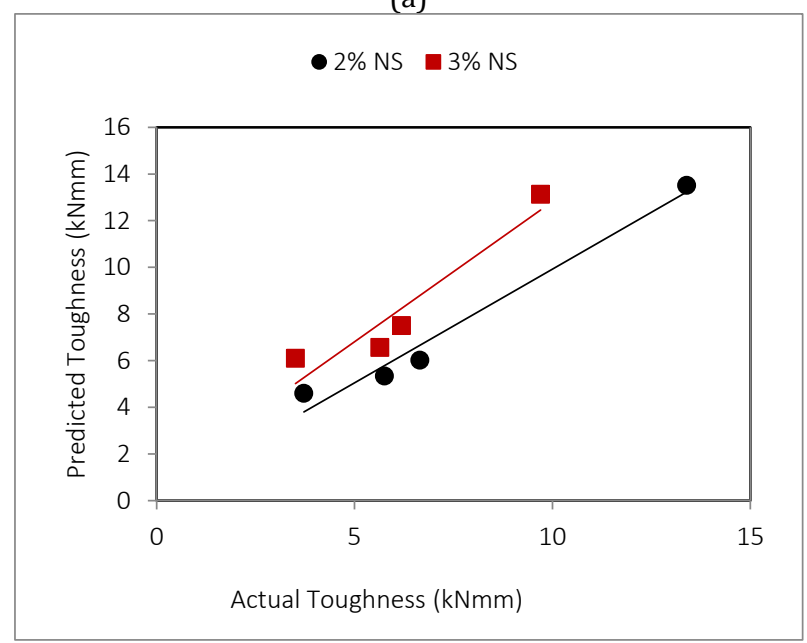

(b)

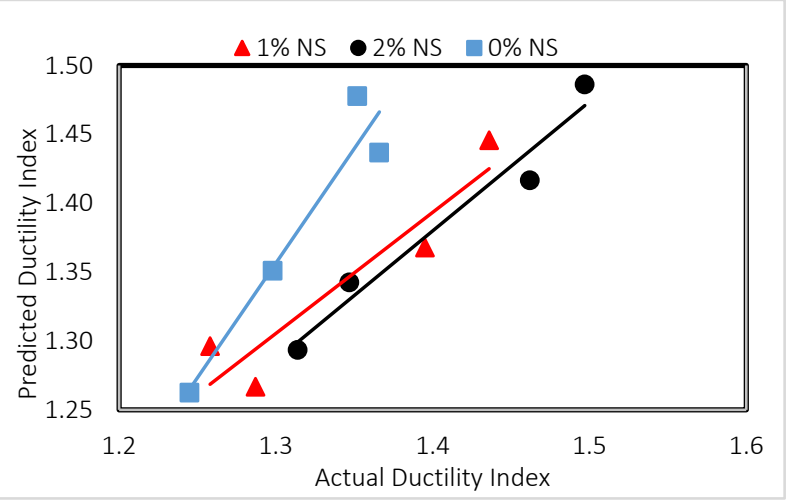

(c)

Fig. 11: predicted Vs. actual plots for a) $0 \%$ NS-1\% NS RCR toughness model b) $2 \%$ NS-3\%NS RCR toughness model c) Ductility index multivariable models

In summary, the RSM model are developed by firstly carrying out design of experiment based on each variable and its percentage variation to obtain the possible run combinations for measuring each response, next is to carry out experimental data collection based on each run combination, then input the data into the RSM to develop the models, and carry out multi-objective variation to validate the model experimentally (Alyamac et al., 2016). In this study the Design expert software version 11.0 was used for the RSM, historical data model was used for developing the mathematical model between the response (flexural toughness), and the variables; crumb rubber (CR), and nano silica (NS). CR variations used are $0 \%, 10 \%, 20 \%$, and $30 \%$ as replacement to fine aggregate by volume. While NS is varied at $0 \%, 1 \%$ and $2 \%$ and $3 \%$ as addition by weight of cementitious materials. A total of 20 run combinations were developed.

\subsubsection{Analysis of variance for RSM models}

The analysis of variance (ANOVA) results for the developed model for flexural toughness with both the insignificant terms and the significant terms removed is shown in Table 5. The 95\% confidence interval $(\mathrm{P}<0.05)$ is used to measure the significant of the response model and all the model terms. A quadratic model type was suitable for predicting the flexural toughness of RCR with the model and model terms (CR, NS, $\mathrm{CR}^{2}$ ) significant having probability $\mathrm{P}$ values $<0.05$, while model terms (CR*NS and $\mathrm{NS}^{2}$ ) insignificant with $\mathrm{P}$-values $>0.05$. Similarly, for ductility index, quadratic model is suitable with the model and all other model terms significant having $\mathrm{P}$-values $<0.05$. The significance of each variance and the responses are evaluated using the 95\% confidence interval which corresponds to probability P-value $<0.05$. Therefore, for the toughness and ductility index model, there is only $0.01 \%$ chance that a model F-value of 18.16 and 13.88, respectively, could occur due to noise. The developed model equation for flexural toughness with the significant and insignificant terms is shown in Eqs. $4 \mathrm{a}$ and $4 \mathrm{~b}$, respectively, and the model for ductility index are shown in Eq. 4c. The positive and negative signs before a model term designate synergistic and antagonistic effect of the individual variable on the flexural toughness of RCR respectively.

$$
\begin{aligned}
& \Delta=4.714+0.055 C R+0.013 N S-0.043 C R * N S+ \\
& 0.0088 C R^{2}-0.058 N S^{2} \\
& \Delta=5.732-0.012 C R-0.803 N S-0.0089 C R^{2} \\
& \Phi=1.31+0.0049 C R-0.065 N S-0.0041 C R * N S+ \\
& 0.0003 C R^{2}+0.031 N S^{2}
\end{aligned}
$$

The coefficient of regression $\left(\mathrm{R}^{2}\right)$ is used to check the adequacy and degree of correlation of the models statistically. As seen in Table 5, ductility index has an $\mathrm{R}^{2}$ of 0.83 while flexural toughness has an $\mathrm{R}^{2}$ value of 0.87 , which mean that the model has only $13 \%$ correlation error. However, removing the insignificant toughness model terms reduces its $\mathrm{R}^{2}$ value to 0.84 . This is because removing the insignificant terms reduces the number of data points which is also included in the calculation of the $\mathrm{R}^{2}$. Furthermore, for both models, their predicted $\mathrm{R}^{2}$ are in agreement with their adjusted $\mathrm{R}^{2}$ as their differences are less than 0.2 (Montgomery, 2008). But for toughness models removing the insignificant terms also increases the predicted $\mathrm{R}^{2}$; this is because the insignificant terms reduce the predictability of the model. The adequacy and degree of correlation of 
the models are checked graphically by plotting normal probability against residuals for flexural toughness and ductility index as shown in Figs. 12a and $12 \mathrm{~b}$ respectively. From both figures it can be seen that the data points were fitted and aligned along the straight line, this implies the predicted model is in agreement with the experimental data and can be used to predict the flexural toughness and ductility index (energy absorption capacity) of RCR with a less residual error.

The predicted versus actual plots for flexural toughness and ductility index is shown in Fig. 13a and Fig. 13b respectively. As seen the predicted and experimental results are in agreement to each other, as they closely fitted the straight line.

The 2D and 3D plots of the flexural toughness and ductility index models are shown in Fig. 14a and 14b and Fig. 15a and 15b, respectively. As seen from Fig. $14 \mathrm{a}$ the contour lines were somehow straight

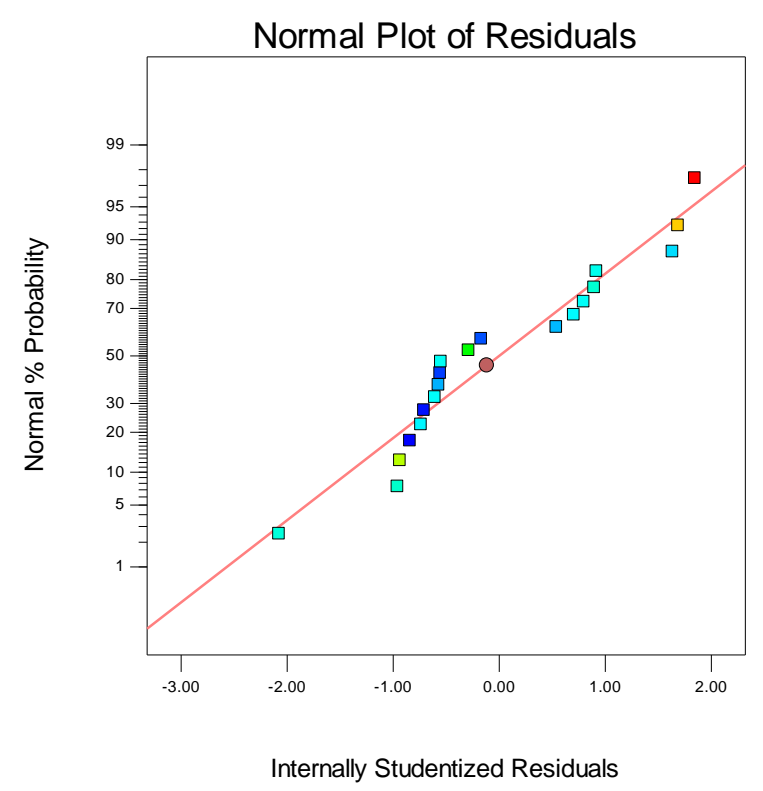

a meaning there is no full interaction (only partial interaction) between the variables, while from Fig. $14 \mathrm{~b}$ the contour lines were oval in shape meaning there is a perfect interaction between the variables (Li et al., 2015).

It can also be seen from both 2D and 3D plots that NS has a negative effect on the ductile behavior of RCR meaning it increases the rigidity of RCR. While CR particles have positive effects on the energy absorption capacity of RCR by making it more ductile. The hot yellowish regions on both plots show the region with the highest toughness and ductility index while the cool blue region is the region with lowest corresponding values. In this case, a combination of $30 \% \mathrm{CR}$ and $0 \%$ NS gives the highest toughness and ductility index while $0 \% \mathrm{CR}$ and $3 \%$ NS gives the lowest toughness values and ductility index.

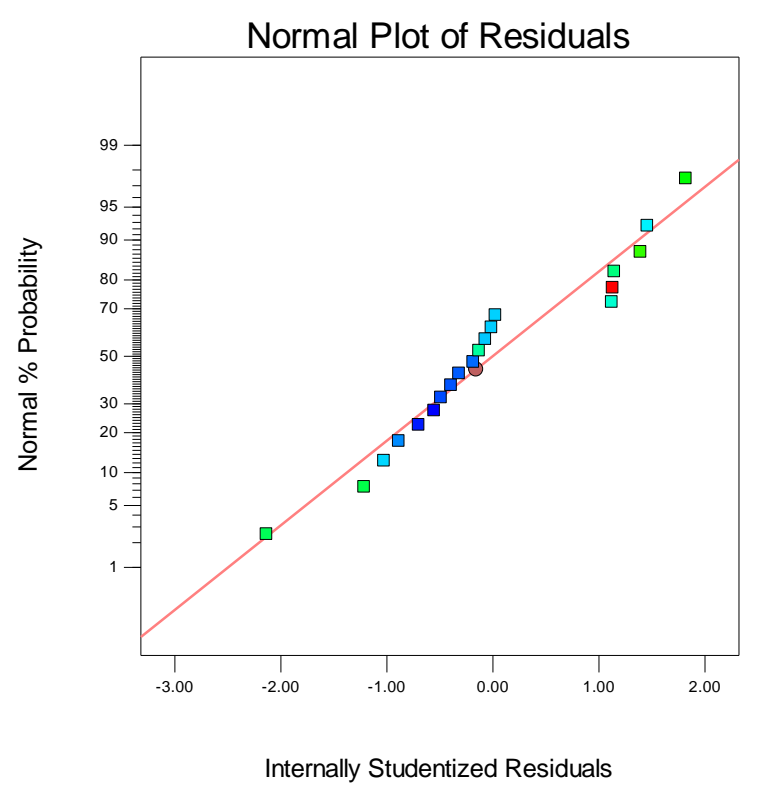

b

Fig. 12: Normal plot of residuals a) for flexural Toughness Model b) for ductility index model

Table 5: ANOVA result for developed model

\begin{tabular}{|c|c|c|c|c|c|c|c|c|c|}
\hline Responses & Factors & F -Values & P-Values & $\mathrm{R}^{2}$ & Adjusted $\mathrm{R}^{2}$ & Predicted $\mathrm{R}^{2}$ & SD & Mean & C.V (\%) \\
\hline \multirow{8}{*}{$\begin{array}{l}\text { Flexural Toughness } \\
\text { (kNmm)-without } \\
\text { insignificant variables }\end{array}$} & Model & 18.16 & $<0.0001$ & \multirow{4}{*}{0.87} & \multirow{4}{*}{0.82} & \multirow{4}{*}{0.67} & \multirow{4}{*}{1.35} & \multirow{4}{*}{7.28} & \multirow{4}{*}{18.53} \\
\hline & NS & 7.40 & 0.0166 & & & & & & \\
\hline & $\mathrm{CR}^{2}$ & 7.92 & 0.0138 & & & & & & \\
\hline & $\mathrm{NS}^{2}$ & 0.035 & 0.8542 & & & & & & \\
\hline & Lack of Fit & 4.86 & $<0.0001$ & & & & & & \\
\hline & CR & 72.23 & $<0.0001$ & \multirow{3}{*}{0.84} & \multirow{3}{*}{0.81} & \multirow{3}{*}{0.72} & \multirow{3}{*}{1.37} & \multirow{3}{*}{7.28} & \multirow{3}{*}{18.83} \\
\hline & NS & 7.16 & 0.016 & & & & & & \\
\hline & Lack of Fit & 152.48 & $<0.0001$ & & & & & & \\
\hline \multirow{3}{*}{ Ductility Index $\Phi$} & Model & 13.88 & $<0.0001$ & \multirow{3}{*}{0.83} & \multirow{3}{*}{0.77} & \multirow{3}{*}{0.63} & \multirow{3}{*}{0.06} & \multirow{3}{*}{1.38} & \multirow{3}{*}{4.06} \\
\hline & CR & 36.01 & $<0.0001$ & & & & & & \\
\hline & NS & 7.53 & 0.0158 & & & & & & \\
\hline
\end{tabular}




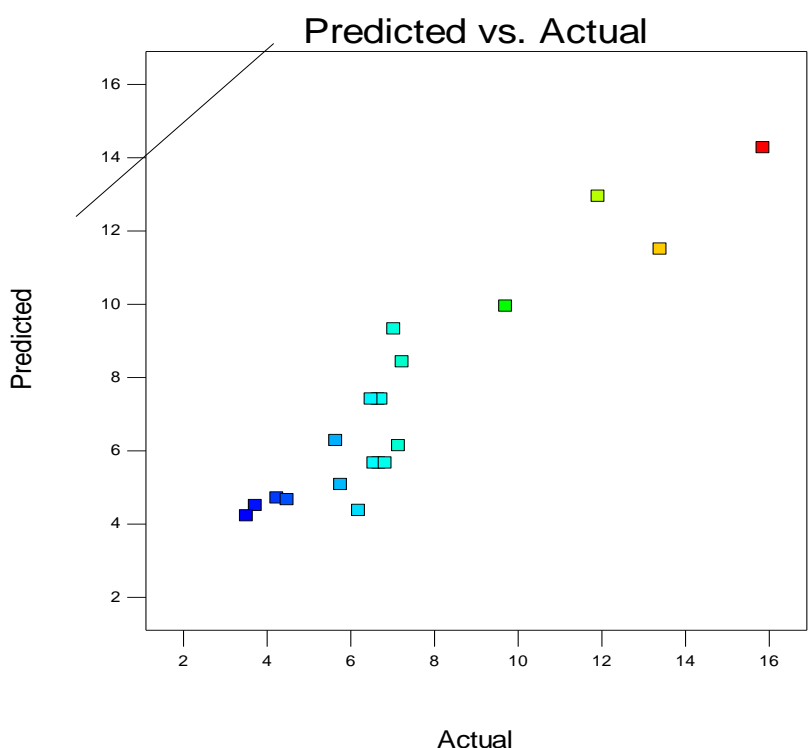

Actual

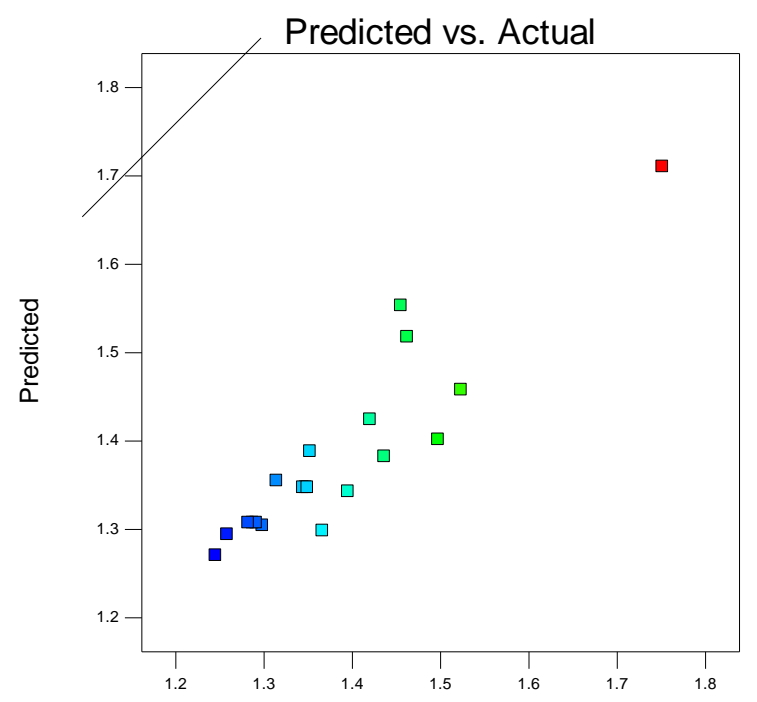

Actual

a

b

Fig. 13: Predicted Vs. actual plots for a) Flexural toughness model b) ductility index model

a

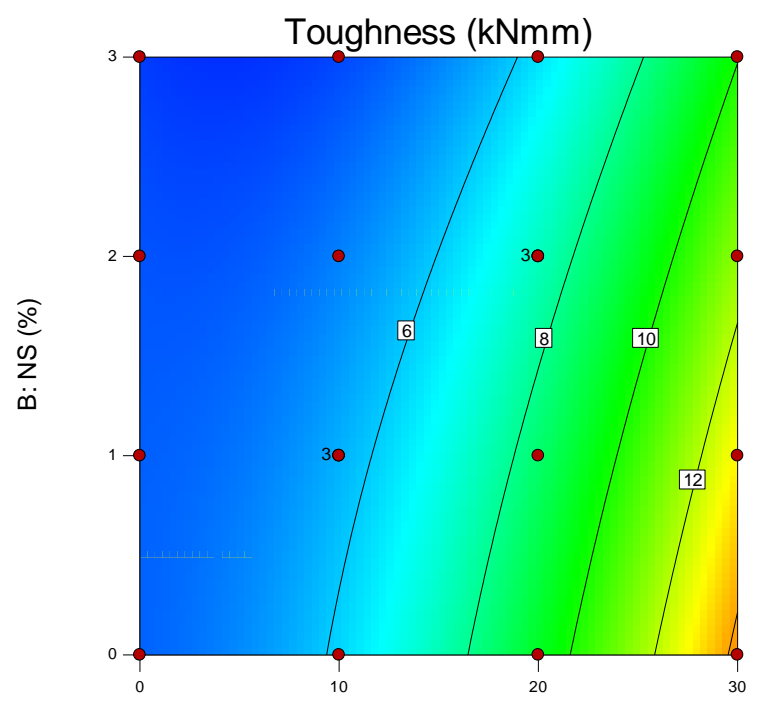

A: CR $(\%)$ b

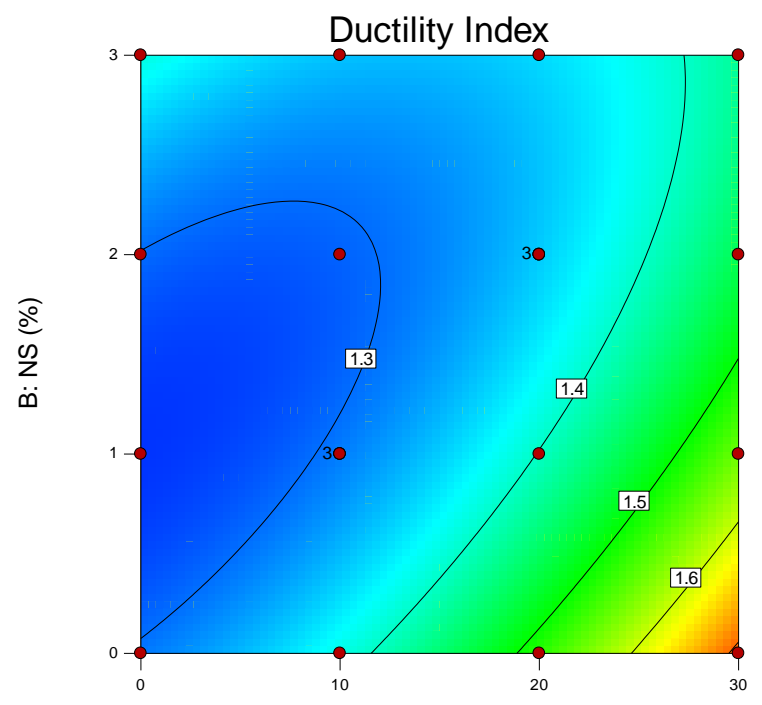

A: CR (\%)

Fig. 14: 2D contour plots for a) Flexural toughness b) Ductility index

\section{Conclusion}

In this paper, the following conclusions can be drawn:

- The flexural strength of RCR increases by partial replacement of fine aggregate with crumb rubber up to $20 \%$, and the addition of up to $2 \%$ NS by weight of cementitious materials.

- The flexural toughness and ductility index of RCR increases with increment in CR and it decreases with increase in percentage addition of NS.

- A quadratic model with a high degree of correlation and predicting ability was developed to predict the flexural toughness of RCR using CR and NS as the variables.
- There is a good correlation between the flexural toughness and compressive strength of RCR for all NS contents.

- The multivariable model can be used to compute the flexural toughness of RCR using load and deflection as the independent variables instead of measuring using the load-deflection curve.

- The flexural toughness and ductility index of RCR with different percentage NS contents can be computed using multivariable regression models using its corresponding compressive strength and flexural strength as the variables, except for ductility index for 3\% NS RCR. 


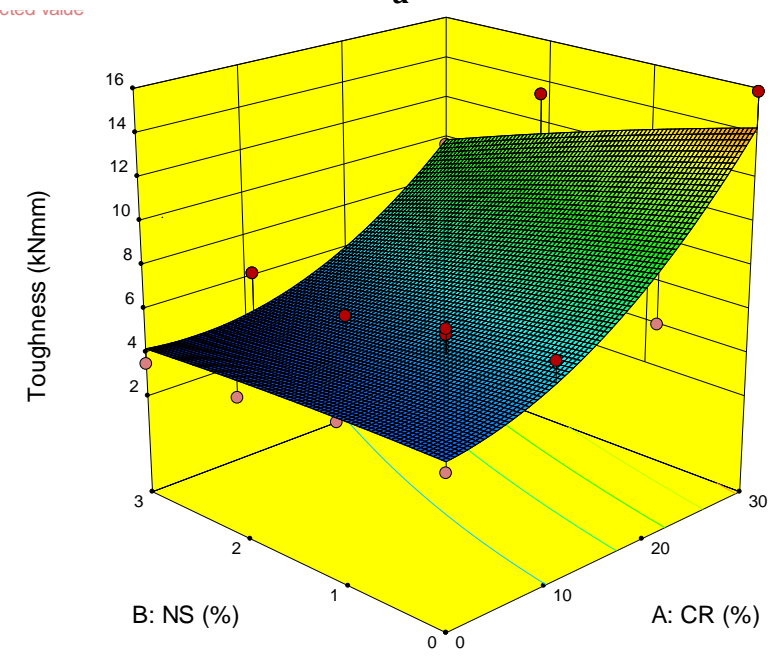

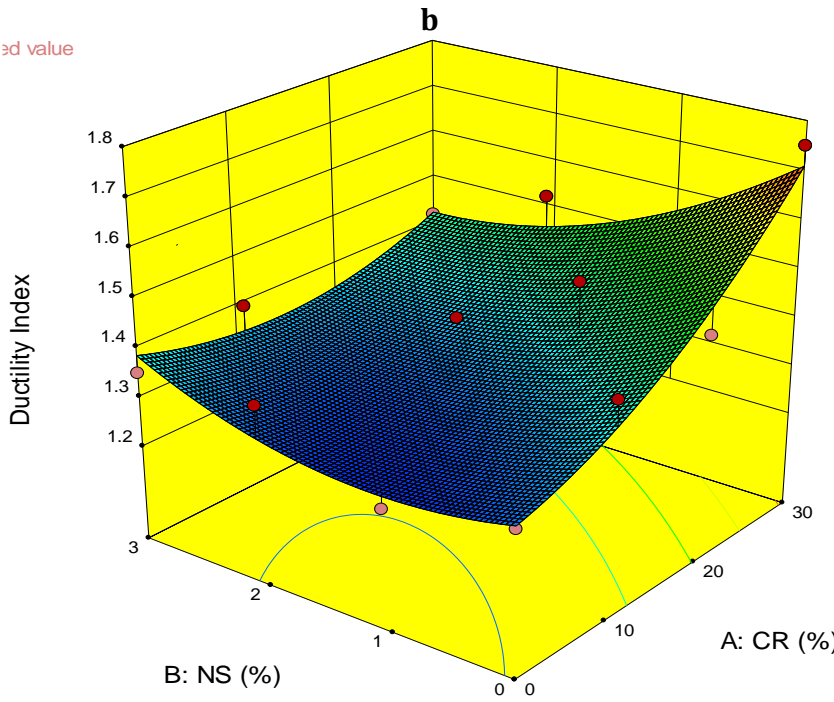

Fig. 15: 3D response surface plot for a) Flexural toughness b) Ductility index

\section{Acknowledgement}

The authors would like to thank the Ministry of Education (MOE) of Malaysia for granting the project under code PRGS/1/13/TK03/UTP/02/02.

\section{References}

ACI (1999). ACI 544-2R: Measurement of properties of fiber reinforced concrete. American Concrete Institute, Michigan, USA.

ACI (2002). ACI 207-5R: Guide for selecting proportions for noslump concrete. American Concrete Institute, Michigan, USA.

ACI (2011). ACI 207-5R: Report on roller-compacted mass concrete. American Concrete Institute, Michigan, USA.

Adamu M, Mohammed BS, and Shafiq N (2016). Nano silica modified roller compacted rubbercrete-an overview. In the Engineering Challenges for Sustainable Future: In the $3^{\text {rd }}$ International Conference on Civil, Offshore and Environmental Engineering (ICCOEE'16), CRC Press, Malaysia: 483-488.

Adamu M, Mohammed BS, and Shafiq N (2017). Effect of mineral filler type on strength of roller compacted rubbercrete for pavement applications. In the $7^{\text {th }}$ International Conference on Key Engineering Materials (ICKEM'17) IOP Conference, 201: 1-5. https://doi.org/10.1088/1757-899X/201/1/012011

Adaska WS (2006). Roller-compacted concrete (RCC). In: Lamond JF (Ed.), Significance of tests and properties of concrete and concrete-making materials. ASTM International, West Conshohocken, USA.

Ahoor AH and Zandi-Atashbar N (2014). Fuel production based on catalytic pyrolysis of waste tires as an optimized model. Energy Conversion and Management, 87: 653-669.

Al-Tayeb MM, Bakar BA, Ismail H, and Akil HM (2013). Effect of partial replacement of sand by fine crumb rubber on impact load behavior of concrete beam: experiment and nonlinear dynamic analysis. Materials and Structures, 46: 1299-1307.

Alyamac KE, Ghafari E, and Ince R (2016). Development of ecoefficient self-compacting concrete with waste marble powder using the response surface method. Journal of Cleaner Production, 144: 192-202.

Amin M and Abu EL-Hassan (2015). Effect of using different types of nano materials on mechanical properties of high strength concrete. Construction and Building Materials, 80: 116-124.
Atahan AO and Yucel AÖ (2012). Crumb rubber in concrete: static and dynamic evaluation. Construction and Building Materials, 36: 617-622

Azmi N, Mohammed BS, and AL-Mattarneh H (2008). Engineering properties of concrete containing recycled tire rubber. In the International Conference on Construction and Building Technology (ICCBT'08), Kuala Lumpur, Malaysia, B(34): 373382. Available online at: http://www.lonestarlab.com/Mar2013/Recycled_Tire_Rubber.pdf

CRD-C (1992). CRD-C 161: Standard practice for selecting proportions for roller compacted concrete (RCC) pavement mixtures using soil compaction concepts. US Army Corps of Engineers, Washington DC, USA.

ERMCO (2013). Guide to roller concrete. European Ready Mixed Concrete Organization, Brussels, Belgium.

Fakhri M (2016). The effect of waste rubber particles and silica fume on the mechanical properties of Roller Compacted Concrete Pavement. Journal of Cleaner Production, 129: 521530.

Grdic Z, Toplicic G, Ristic N, Grdic D, and Metkovic P (2014). Hydro-abrasive resistance and mechanical properties of rubberized concrete. Građevinar, 66:11-20.

Hilal NN (2017). Hardened properties of self-compacting concrete with different crumb rubber size and content. International Journal of Sustainable Built Environment, 6(1): 191-206.

Kardos AJ and Durham SA (2015). Strength, durability, and environmental properties of concrete utilizing recycled tire particles for pavement applications. Construction and Building Materials, 98: 832-845.

Li Q, Cai L, Fu Y, Wang H, and Zou Y (2015). Fracture properties and response surface methodology model of alkali-slag concrete under freeze-thaw cycles. Construction and Building Materials, 93: 620-626.

Liu F, Meng LY, Ning GF, and Li J (2015). Fatigue performance of rubber-modified recycled aggregate concrete (RRAC) for pavement. Construction and Building Materials, 95: 207-217.

Mansour F and Ershad A (2017). Crack behavior analysis of roller compacted concrete mixtures containing reclaimed asphalt pavement and crumb rubber. Engineering Fracture Mechanics, 180: 43-59.

Mehta P and Monteiro P (2006). Concrete-microstructure, properties and materials. McGraw Hill, University of California, Berkeley, USA. 
Moghaddam TB, Karim MR, and Abdelaziz M (2011). A review on fatigue and rutting performance of asphalt mixes. Scientific Research and Essays, 6(4): 670-682.

Mohammed AM (2015). Influence of nano materials on flexural behavior and compressive strength of concrete. HBRC Journal, 12(2): 212-225.

Mohammed BS (2010). Structural behavior and $\mathrm{m}-\mathrm{k}$ value of composite slab utilizing concrete containing crumb rubber. Construction and Building Materials, 24: 1214-1221.

Mohammed BS and Azmi N (2014). Strength reduction factors for structural rubbercrete. Frontiers of Structural and Civil Engineering, 8: 270-281.

Mohammed BS, Awang AB, Wong SS, and Nhavene CP (2016). Properties of nano silica modified rubbercrete. Journal of Cleaner Production, 119: 66-75.

Mohammed BS, Azmi NJ, and Abdullahi M (2011). Evaluation of rubbercrete based on ultrasonic pulse velocity and rebound hammer tests. Construction and Building Materials, 25: 13881397.

Mohammed BS, Hossain KMA, Swee JTE, Wong G, and Abdullahi M (2012). Properties of crumb rubber hollow concrete block. Journal of Cleaner Production, 23: 57-67.

Montgomery DC (2008). Design and analysis of experiments. John Wiley \& Sons, New Jersey, USA.

Moustafa A and Elgawady MA (2015). Mechanical properties of hmigh strength concrete with scrap tire rubber. Construction and Building Materials, 93: 249-256.
Mukharjee BB and Barai SV (2014). Influence of nano-silica on the properties of recycled aggregate concrete. Construction and Building Materials, 55: 29-37.

Ozbay E, Lachemi M, and Sevim UK (2011). Compressive strength, abrasion resistance and energy absorption capacity of rubberized concretes with and without slag. Materials and Structures, 44: 1297-1307.

Sengoz B and Topal A (2005). Use of asphalt roofing shingle waste in HMA. Construction and Building Materials, 19: 337-346.

Siddique R (2007). Waste materials and by-products in concrete. Springer Science and Business Media, Berlin, Germany.

Thomas BS and Gupta RC (2015). Properties of high strength concrete containing scrap tire rubber. Journal of Cleaner Production, 113: 86-92.

Yilmaz A and Degirmenci N (2009). Possibility of using waste tire rubber and fly ash with Portland cement as construction materials. Waste Management, 29: 1541-1546.

Youssf O, Elgawady MA, Mills JE, and Ma X (2014). An experimental investigation of crumb rubber concrete confined by fibre reinforced polymer tubes. Construction and Building Materials, 53: 522-532.

Youssf O, Mills JE, and Hassanli R (2016). Assessment of the mechanical performance of crumb rubber concrete. Construction and Building Materials, 125: 175-183.

Zheng L, Hou XS, and Yuan Y (2008). Strength, modulus of elasticity, and brittleness index of rubberized concrete. Journal of Materials in Civil Engineering, 20: 692-699. 